\title{
Surgery for Gastrointestinal Stromal Tumours (GISTs) in Australia and New Zealand: results from a bi-national audit
}

\section{AUTHORS}

Parameswaran $\mathrm{R}^{1}$, Roberts $\mathrm{RH}^{2}$, Brown $\mathrm{WA}^{3}$, Aly $\mathrm{A}^{4}$, Kiroff $\mathrm{G}^{5}$, Epari $\mathrm{K}^{6}$,

MacCormick $\mathrm{AD}^{7}$, Thomson $\mathrm{I}^{8}$, Thompson $\mathrm{SK}^{1,9}$

${ }^{1}$ University of Adelaide, Royal Adelaide Hospital, Adelaide, South Australia, Australia

${ }^{2}$ Christchurch Hospital, Christchurch, New Zealand

${ }^{3}$ Monash University, Melbourne, Victoria, Australia

${ }^{4}$ The Austin Hospital, Melbourne, Victoria, Australia

${ }^{5}$ The Queen Elizabeth Hospital, Woodville South, South Australia, Australia

${ }^{6}$ Fiona Stanley Hospital, Murdoch, Western Australia, Australia

${ }^{7}$ The University of Auckland, Auckland, New Zealand

${ }^{8}$ Princess Alexandria Hospital, Brisbane, Queensland, Australia

${ }^{9}$ University of South Australia, Adelaide, South Australia, Australia

\section{CORRESPONDING AUTHOR}

Associate Professor Sarah K Thompson. Discipline of Surgery, Level 5, Eleanor Harrald Building, Royal Adelaide Hospital, North Terrace, Adelaide, South Australia, 5000. Email: Sarah.Thompson@adelaide.edu.au. Ph: +61 882674092.

This is the author manuscript accepted for publication and has undergone full peer review but has not been through the copyediting, typesetting, pagination and proofreading process, which may lead to differences between this version and the Version of Record. Please cite this article as doi: $10.1111 /$ ans. 13840 


\section{WORD COUNT}

1,200 (Main document including Acknowledgments and References)

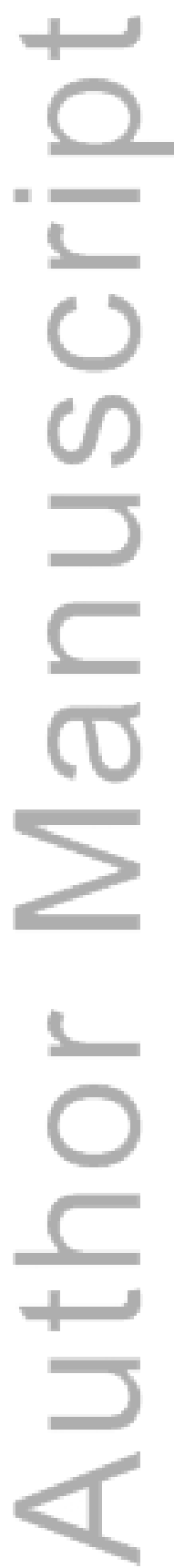

This article is protected by copyright. All rights reserved. 


\section{INTRODUCTION}

Gastrointestinal stromal tumours (GISTs) are the most common mesenchymal tumours of the gastrointestinal tract and account for $1-2 \%$ of all gastrointestinal malignancies ${ }^{1}$. In terms of metastatic potential, GISTs encompass a continuum of small, mitotically inactive tumours up to larger, active tumours'. Surgical resection is considered standard of care for localised GISTs.

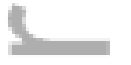

Population-based studies have been published from 19 countries, and they report annual incidence rates between 4.3 and 22 per million ${ }^{1,2}$. There is no published data from Australia, and one recent review from New Zealand ${ }^{3}$.

Given the relative rarity of GISTs, the bi-national Australia \& New Zealand Gastric \& Oesophageal Surgery Association (ANZGOSA) audit, commenced in 2010, is ideally suited to determine disease burden, tumour characteristics, and treatment patterns of GISTs, including incidence if possible, in Australia and New Zealand.

This article is protected by copyright. All rights reserved. 


\section{METHODS}

The ANZGOSA Audit is an ongoing quality assurance activity of ANZGOSA aiming to document patterns of care of patients undergoing surgery for oesophago-gastric cancer. Participation is voluntary and currently data are being collected at 56 Australian hospitals and 6 New Zealand hospitals (66 ANZGOSA surgeons). Audit data is uploaded to a database, which is maintained and managed by the Royal Australasian College of Surgeons (www.surgeons.org/anzgosa ).

\section{Baseline Demographics and Pathological Characteristics}

Patient demographics and pathological characteristics were collected. A final diagnosis of GIST was based on pathology. Size $(\mathrm{cm})$ and mitotic index were determined to calculate the risk of recurrence according to the modified National Institute of Health $(\mathrm{NIH})$ criteria ${ }^{1}$.

\section{Operative Outcomes}

Information was collected regarding perioperative outcomes. Postoperative morbidity was classified into surgical and non-surgical causes.

\section{Incidence Rates}

The annual incidence of GIST was calculated per million population during the period 2012 to 2014 , using population data for the same time period. 


\section{RESULTS}

\section{Baseline Demographics and Pathological Characteristics}

Two hundred and eighty patients underwent resection of a GIST between 2007 and 2015 . The majority of these patients were from Australia (90\%) with a median age of 67 years (range 19-103 years), and a slight male preponderance (143 males, 51\%).

The majority of tumours were GISTs (98\%). Six tumours were not GIST on final pathology, and five were further identified as glomus tumour, schwannoma (2), leiomyoma, and pancreatic heterotopia. Most GISTs were located in the gastric fundus (95 cases; 34\%) and body (93 cases; 33\%), with the remainder in the antrum (38), distal oesophagus (5), gastro-oesophageal junction (5), pylorus (3), small intestine (25), and unknown (16).

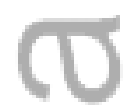

Less than half of the cases were discussed at multidisciplinary meetings prior to definitive treatment but in one third of cases (36\%), this data point was missing. One hundred and forty-eight (53\%) were very low risk for recurrence, $12(4 \%)$ were low risk, $46(16 \%)$ were intermediate, and $45(16 \%)$ were in the high-risk group. Information on resection margins was available in 239 patients of which 208 (87\%) patients had a negative margin.

\section{Operative Outcomes}

The most common operation performed was local excision in $240(86 \%)$ patients. A laparoscopic approach was employed in $227(81 \%)$ of patients, which was converted to an 
open approach in eight (3\%) patients. A more extensive gastrectomy was performed in 34 (12\%) patients. Six patients underwent oesophagectomy.

The 30-day mortality and in-hospital death rate was zero. Seven patients $(2.5 \%)$ had an unplanned return to theatre. Reasons included staple line bleed / leak, staple line resection for positive margin, port site hernia, caecal volvulus, anastomotic leak, and endoscopic dilatation of gastric sleeve post-resection. The median length of in-hospital stay was five days (range 1 - 77 days). Thirty-one patients (11\%) had post-operative complications: 14 surgical and 17 non-surgical causes.

\section{Incidence rates}

Looking at the two cities where a well-established database is used to capture all surgically managed GIST cases (i.e. Adelaide with a population of 1,286,700 in 2013; Brisbane with a population of 2,240,000 in 2013), the incidence of GIST was 13.6 per million per year.

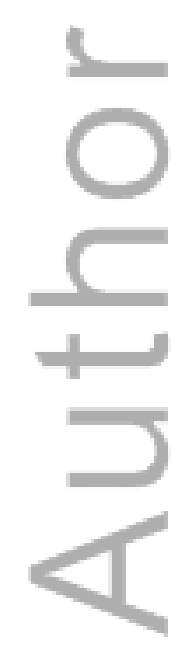




\section{DISCUSSION}

Two hundred and eighty GIST cases were reported to the ANZGOSA audit between 2007 and 2015. Of importance, there was a zero 30-day mortality, and an $11 \%$ risk of morbidity. These results are consistent with other multi-centre studies, demonstrating resection of gastric GISTs to be a safe procedure with acceptable rates of mortality and morbidity ${ }^{4}$.

The distribution of $\mathrm{NIH}$ risk categories in primary GISTs showed a surprising number of intermediate or high-risk cases for recurrence (36\%). This is in keeping with many epidemiological studies from other countries, showing a significant number of intermediate and high-risk cases ${ }^{1,2}$. Part of the reason for this may be selection bias, as our bi-national audit only captures those patients undergoing surgical resection. Most surgeons will elect to treat GISTs $<2 \mathrm{~cm}$ in size conservatively, based on the NCCN task force report'.

An annual incidence of 13.6 per million head of population was found in Adelaide and Brisbane, in keeping with the most recent epidemiological paper on $\mathrm{GIST}^{2}$. A much lower annual incidence was found in the remaining Australian states and New Zealand, perhaps indicating less than perfect capture of new GIST cases in those regions to our bi-national audit.

Whilst there were limitations to our study, such as a selection bias towards more aggressive/larger GISTs, a lack of survival outcomes, and less than perfect capture for each data point described above, this is still the largest series of GISTs reported from 
Australia and New Zealand. Current issues for ANZGOSA include funding of the binational Audit, and better capture of cases. In comparison to the long standing BreastSurgANZ Quality Audit, where full members are required to submit data on all cases of non-metastatic breast cancer, the ANZGOSA Audit is a voluntary quality assurance activity, which fulfills current requirements for Continuing Professional Development (Category 1). It is hoped that, with streamlining the audit to several key performance indicators, the ANZGOSA Audit will become more attractive to funders and surgeons. Data from a more focused ANZGOSA Audit can then be used by local hospitals across Australia and New Zealand to benchmark quality and safety against a national standard. For a rare disease such as GIST, the ANZGOSA Audit may prove invaluable in determining epidemiology/tumour burden, and patterns of care across Australia and New Zealand.

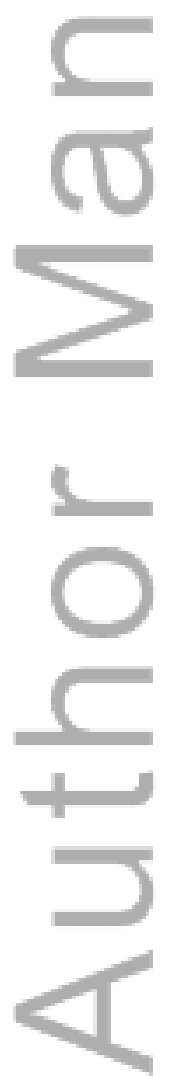




\section{ACKNOWLEDGMENTS}

We wish to acknowledge the initial work from A/Prof Garett Smith and Prof Mark Smithers in the inception of the ANZGOSA Audit, and the immense efforts of Michelle Ogilvy, Team Leader, Katherine Economides, Manager, and Louise Kennedy, Data Administrator, without whom the Audit would not exist. Funding for the audit is provided from previously sponsored monies from Novartis, and Johnson \& Johnson Medical.

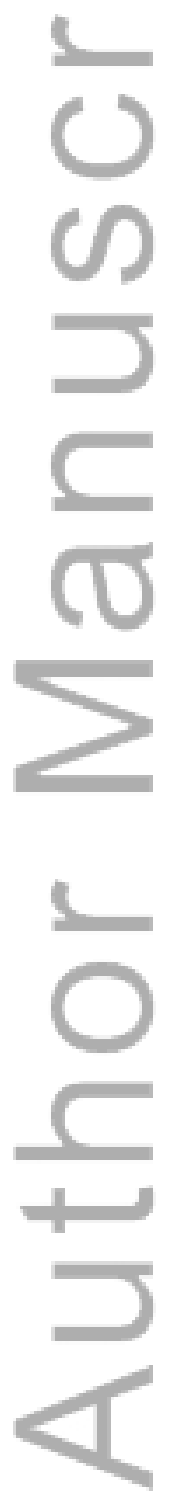

This article is protected by copyright. All rights reserved. 


\section{REFERENCES}

1. Demetri GD, von Mehren M, Antonescu CR et al. NCCN Task Force report: update on the management of patients with gastrointestinal stromal tumors. $J$ Natl. Compr. Canc. Netw. 2010; 8:S1-S41.

2. Søreide K, Sandvik OM, Søreide JA et al. Global epidemiology of gastrointestinal stromal tumours (GIST): a systematic review of population-based cohort studies. Cancer Epidemiol. 2016; 40:39-46.

3. Siu J, Lim M, Fischer $\mathrm{J}$ et al. Ten-year review of gastrointestinal stromal tumours at a tertiary referral hospital in New Zealand. ANZ J. Surg. 2016; 86:162-6.

4. Piessen $\mathrm{G}$, Lefevre $\mathrm{JH}$, Cabau $\mathrm{M}$ et al. Laparoscopic versus open surgery for gastric gastrointestinal stromal tumors: what is the impact on postoperative outcome and oncologic results? Ann. Surg. 2015; 262: 831-40. 


\section{University Library}

\section{- M M N E R VA A gateway to Melbourne's research publications}

Minerva Access is the Institutional Repository of The University of Melbourne

\section{Author/s:}

Parameswaran, R;Roberts, RH;Brown, WA;Aly, A;Kiroff, G;Epari, K;MacCormick, AD; Thomson, IG;Thompson, SK

Title:

Surgery for gastrointestinal stromal tumours in Australia and New Zealand: results from a binational audit

Date:

2017-04-01

Citation:

Parameswaran, R., Roberts, R. H., Brown, W. A., Aly, A., Kiroff, G., Epari, K., MacCormick, A. D., Thomson, I. G. \& Thompson, S. K. (2017). Surgery for gastrointestinal stromal tumours in Australia and New Zealand: results from a bi-national audit. ANZ JOURNAL OF SURGERY, 87 (4), pp.220-221. https://doi.org/10.1111/ans.13840.

Persistent Link:

http://hdl.handle.net/11343/292726 